\title{
Exogenous erythropoietin administration attenuates intermittent hypoxia-induced cognitive deficits in a murine model of sleep apnea
}

\author{
Ehab A Dayyat ${ }^{1+}$, Shelley X Zhang ${ }^{1+}$, Yang Wang ${ }^{1}$, Zixi Jack Cheng ${ }^{2}$ and David Gozal ${ }^{1 *}$
}

\begin{abstract}
Background: In rodents, exposure to intermittent hypoxia $(I H)$, a hallmark of obstructive sleep apnea (OSA), is associated with neurobehavioral impairments, increased apoptosis in the hippocampus and cortex, as well as increased oxidant stress and inflammation. Such findings are markedly attenuated in rodents exposed to sustained hypoxia 9SH) of similar magnitude. The hypoxia-sensitive gene erythropoietin (EPO) has emerged as a major endogenous neuroprotectant, and could be involved in $\mathrm{H}$-induced neuronal dysfunction.
\end{abstract}

Methods and Results: $\| \mathrm{H}$ induced only transiently increased expression of EPO mRNA in hippocampus, which was continued in (SH)-exposed mice. $\mathrm{IH}$, but not $\mathrm{SH}$, adversely affected two forms of spatial learning in the water maze, and increased markers of oxidative stress. However, on a standard place training task, mice treated with exogenously administered EPO displayed normal learning, and were protected from the spatial learning deficits observed in vehicle-treated $(\mathrm{C})$ littermates exposed to $\mathrm{IH}$. Moreover, anxiety levels were increased in $\mathrm{IH}$ as compared to normoxia, while no changes in anxiety emerged in EPO-treated mice. Additionally, C mice, but not EPO-treated IH-exposed mice had significantly elevated levels of NADPH oxidase expression, as well as increased MDA and 8-OHDG levels in cortical and hippocampal lysates.

Conclusions: The oxidative stress responses and neurobehavioral impairments induced by $\mathbb{H}$ during sleep are mediated, at least in part, by imbalances between EPO expression and increased NADPH oxidase activity, and thus pharmacological agents targeting EPO expression in CNS may provide a therapeutic strategy in sleep-disordered breathing.

\section{Background}

Obstructive Sleep Apnea (OSA), a disorder characterized by repeated episodes of upper airway obstruction during sleep, is now recognized as a major health problem in all age groups, leading not only to significant cardiovascular and metabolic morbidity, but also to cognitive and behavioral deficits. The neurobehavioral impairments are associated with increased levels of oxidative stress and inflammatory markers, and reversible gray matter losses

\footnotetext{
*Correspondence: dgozal@uchicago.edu

${ }^{\dagger}$ Equal contributors

'Department of Pediatrics, Pritzker School of Medicine, Comer Children's Hospital, The University of Chicago, 5721 S. Maryland Avenue, Suite K-160, Chicago, IL MC 8000, USA

Full list of author information is available at the end of the article
}

in neural sites contributing to cognitive function have been repeatedly described [1-5]. The episodic hypoxiareoxygenation cycles during sleep that characterize OSA have been replicated in rodent models, and shown to elicit neurodegenerative changes, increased oxidant stress and inflammation, and impaired hippocampusdependent learning [6-16]. However, exposures to sustained hypoxia of similar severity and duration are not associated with major cognitive deficits [3], suggesting that intrinsic differences in the presentation of the hypoxic stimulus elicit differential genomic and proteomic cellular responses that ultimately lead to divergent susceptibility.

Erythropoietin (EPO), a prototypic cytokine and hypoxia-sensitive gene, has been recently implicated in

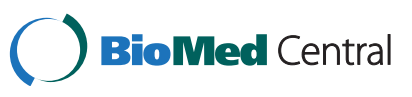


affording neuroprotection in conditions such as severe brain hypoxia or ischemia [1,17-20]. However, the time course of EPO expression during IH conditions mimicking OSA has not been specifically examined. We hypothesized that $\mathrm{IH}$ would elicit reduced induction of EPO expression when compared to sustained hypoxia conditions, which is not associated with significant deficits in hippocampal long-term potentiation [11]. Furthermore, we hypothesized that exogenous administration of recombinant human EPO would attenuate $\mathrm{IH}$-induced NADPH oxidase mediated hippocampal oxidative stress injury and cognitive and behavioral deficits. In addition, we also tested the effect of EPO treatment on other behavioral paradigms for anxiety and depression, since such problems are frequently encountered in patients with sleep apnea, as well as with IH-exposures [21].

\section{Methods}

\section{Animals}

Male C57BL/6J mice (20-22 grams) were purchased from Jackson Laboratories (Bar Harbor, Maine), housed in a $12 \mathrm{hr}$ light/dark cycle (lights on from 7:00 am to 7:00 pm) at a constant temperature $\left(26 \pm 1^{\circ} \mathrm{C}\right)$. Mice were housed in groups of four in standard clear polycarbonate cages, and were allowed access to food and water ad libitum. All behavioral experiments were performed during the light period (between 9:00 am and 12:30 pm). Mice were randomly assigned to either $\mathrm{IH}, \mathrm{SH}$, or room air (RA) exposures. The experimental protocols were approved by the Institutional Animal Use and Care Committee and are in close agreement with the Guide in the Care and Use of Animals. All efforts were made to minimize animal suffering and to reduce the number of animals used.

In a subset of mice, treatment with recombinant human erythropoietin (rhEPO; Roche, Mannheim, Germany) was carried out for the duration of $\mathrm{IH}$ exposures and until all behavioral testing was completed. rhEPO was dissolved in $0.1 \mathrm{~mol} / \mathrm{L}$ phosphate-buffered saline (PBS) containing $0.1 \%$ mouse serum albumin (Sigma) at a stock concentration of $2500 \mathrm{IU} / \mathrm{mL}$. EPO-vehicle consisted of PBS containing $0.1 \%$ mouse serum albumin. rhEPO was delivered by intraperitoneal (IP) injection at a dose of $5000 \mathrm{IU} / \mathrm{kg}$ body weight in a daily fashion. EPO-vehicle was delivered by IP injection with a volume corresponding to that of rhEPO injection. This dosage has been shown to effectively cross the blood brain barrier in rodents [22-24].

\section{Intermittent and sustained hypoxia exposures}

Animals were maintained in 4 identical commerciallydesigned chambers (30"x20"x20"; Oxycycler model A44XO, BioSpherix, Redfield, NY) operated under a 12 hour light-dark cycle (7:00 am-7:00 pm) for 14 days prior to behavioral testing. Oxygen concentration was continuously measured by an $\mathrm{O}_{2}$ analyzer, and was changed by a computerized system controlling gas outlets, as previously described [10], such as to generate stable initial oxyhemoglobin nadir values $(\mathrm{SaO} 2)$ in the $65-72 \%$ range for $\mathrm{SH}$, and alternating every 180 seconds with normoxia $(\mathrm{SaO} 2>95 \%)$ for $\mathrm{IH}$ conditions. In addition, time-matched normoxic exposures (RA) were conducted. Ambient temperature was kept at $22-24^{\circ} \mathrm{C}$.

\section{Behavioral testing}

The Morris water maze was used to assess spatial reference learning and memory, as well as working memory. The maze protocol is similar to that described by Morris [25] with modifications for mice. The maze consisted of a white circular pool, $1.4 \mathrm{~m}$ in diameter and $0.6 \mathrm{~m}$ in height, filled to a level of $35 \mathrm{~cm}$ with water maintained at a temperature of $21^{\circ} \mathrm{C}$ (Morris 1984). Pool water was made opaque by addition of $150 \mathrm{ml}$ of non-toxic white tempera paint. A Plexiglas escape platform $(10 \mathrm{~cm}$ in diameter) was positioned $1 \mathrm{~cm}$ below the water surface and placed at various locations throughout the pool. Extramaze cues surrounding the maze were located at fixed locations, and visible to the mice while in the maze. Maze performance was recorded by a video camera suspended above the maze and interfaced with a video tracking system (HVS Imaging, Hampton, UK).

Briefly, a standard place-training reference memory task was initiated and conducted for 6 days on mice in the water maze following exposures to 14 days of $\mathrm{IH}$, $\mathrm{SH}$, or RA. One day prior to place learning, mice were habituated to the water maze during a free swim. Place learning was then assessed over six consecutive days using a spaced training regimen that has been demonstrated to produce optimal learning in mice [26]. Each training session consisted of three trials separated by a 10 minute inter-trial interval (ITI). On a given daily session, each mouse was placed into the pool from 1 of 4 quasirandom start points $(\mathrm{N}, \mathrm{S}, \mathrm{E}$ or $\mathrm{W})$ and allowed a maximum of 90 seconds to escape to the platform where the mice were allowed to stay for $15 \mathrm{sec}$. Mice that failed to escape were led to the platform. The position of the platform remained constant during the trials. $24 \mathrm{~h}$ following the final training session, the platform was removed for a probe trial to obtain measures of spatial bias. To assess the performance in the water maze, mean escape latencies and swim distance were analyzed.

\section{Reference memory}

Retention tests were carried out 14 days after acquisition of the task. In the retention test, performance in a single session (two trials) was assessed, and the mean average performance of the two trials was calculated. 


\section{Elevated plus maze (EPM)}

The elevated plus maze (EPM) was used to assess anxiety. The basic measure is the animal preference for dark, enclosed places over bright, exposed places [27,28]. A $60 \mathrm{w}$ light was placed above the apparatus and the test was video taped by an overhead camera. Mice were placed in the center of the maze facing a closed arm, and allowed to explore for $10 \mathrm{~min}$ in isolation. Each mouse received one videotaped trial. Mice prefer to enter into closed arms compared to open arms. Time spent in the dark area is viewed as avoidance or anxiety-like behavior. The following parameters were scored: (a) Percent time spent in open and closed arms; (b) number of entries to closed arms; (c) Time spent in the center. An arm entry was defined as the entry of all four feet into either one of the closed arm. Of note, the maze was cleaned with $30 \%$ ethanol between trials to remove any odor cues.

\section{Forced swimming test (FST)}

Briefly, mice were individually forced to swim in an open cylindrical container (diameter $14 \mathrm{~cm}$, height $20 \mathrm{~cm}$ ), with a depth of $15 \mathrm{~cm}$ of water at $25 \pm 1^{\circ} \mathrm{C}$. The immobility time, defined as the absence of escape-oriented behaviors, was scored during $6 \mathrm{~min}$, as previously described [29-31]. Each mouse was judged to be immobile when it ceased struggling, and remained floating motionless in the water, making only those movements necessary to keep its head above water. The average percentage immobility was calculated by a blinded experimenter.

\section{Erythropoietin and NADPH oxidase expression}

qRT-PCR analysis of EPO, EPO receptor, and p47phox was performed using ABI PRISM 7500 System (Applied Biosystems, Foster City, CA). PCR Primers and Taqman probes for EPO and p47phox were purchased from $A B I$

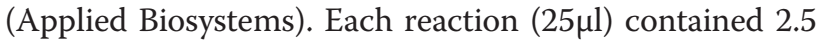
$\mu \mathrm{l}$ reaction buffer (10x), $6 \mathrm{mM} \mathrm{MgCl} 2,0.2 \mu \mathrm{M}$ dNTP, $0.6 \mu \mathrm{M}$ each primer, $0.25 \mu \mathrm{l}$ SureStar Taq DNA Polymerase and $2 \mu \mathrm{l}$ cDNA dilutions. The cycling condition consisted of 1 cycle at $95^{\circ} \mathrm{C}$ for $10 \mathrm{~min}$ and 40 threesegment cycles $\left(95^{\circ} \mathrm{C}\right.$ for $30 \mathrm{~s}, 55^{\circ} \mathrm{C}$ for $60 \mathrm{~s}$ and $72^{\circ} \mathrm{C}$ for $30 \mathrm{~s})$. Standard curves for gene of interest and housekeeping gene ( $\beta$-actin) were included in each reaction. We found that the mRNA expression of $\beta$-actin was stable after $\mathrm{IH}$ or $\mathrm{SH}$ exposures. Expression values were obtained from the cycle number (Ct value) using the MX4000 software (Stratagene, La Jolla, CA). EPO, P47phox, and $\beta$-actin mRNA were performed in triplicates to determine the $\mathrm{Ct}$-diff. These $\mathrm{Ct}$ values were averaged and the difference between the $\beta$-actin $\mathrm{Ct}$ (Avg) and the gene of interest Ct (Avg) was calculated (Ct-diff). The relative expression EPO and p47phox was analyzed using the $2^{-\Delta \Delta \mathrm{CT}}$ method. Quantitative results were expressed as the mean \pm standard deviation (SD).

\section{Immunohistochemistry}

Animals were deeply anesthetized and perfused intracardially with $4 \%$ phosphate-buffered paraformaldehyde. Serial sections were cut on a microtome. The free floating sections were incubated with a goat anti-mouse polyclonal EPO antibody(1:200 dilution; LS Biosciences;LS-C128821) and anti-NeuN (1:1000 dilution; Millipore, clone A60). Immunostained sections were further visualized with FITC-conjugated or rhodamine-conjugated 2nd antibody. Sections were initially assessed using a Nikon Ellipse E800 microscope, and subsequently with a confocal microscope (Leica TCS SP5). To present the expression patterns in a complete fashion, a montage of photomicrographs was assembled using Adobe Photoshop 8.0.

\section{Lipid peroxidation assay}

MDA-586 kits (OxisResearch, Portland OR) were used to measure the relative malondialdehyde (MDA) production, a commonly used indicator of lipid peroxidation [31], in frontal brain cortex according to the manufacturer's instructions. Briefly, after anesthesia with pentobarbital (50 mg/kg intraperitoneally), mice were perfused with $0.9 \%$ saline buffer for 5 minutes and the cortex was dissected, snap frozen in liquid nitrogen, and stored at $-80^{\circ} \mathrm{C}$ until assay the following day. Cortical and hippocampal tissues were homogenized in $20 \mathrm{mM}$ phosphate buffer (pH 7.4) containing $0.5 \mathrm{mM}$ butylated hydroxytoluene to prevent sample oxidation. After protein concentration measurements, equal amounts of proteins (2.0-2.5 mg protein from each sample) were used in triplicate to react with chromogenic reagents at $45^{\circ} \mathrm{C}$ in $500 \mu \mathrm{L}$ buffer for 2 hours. The samples were then centrifuged and clear supernatants measured at 586 $\mathrm{nm}$. The level of MDA production was then calculated with the standard curve obtained from the kit according to the manufacturer's instructions.

\section{8-hydroxydeoxyguanosine (8-OHDG) tissue levels}

Levels of 8-OHDG were measured in frontal brain cortex and hippocampus using a commercially available assay (Cell Biolabs, San Diego, CA). Briefly, cortical samples or 8-OHDG standards were first added to an 8OHDG/BSA conjugate preabsorbed enzyme immunoassay plate. After a brief incubation, an anti-8-OHDG $\mathrm{mAb}$ was added, followed by an horseradish peroxidaseconjugated secondary antibody. The 8-OHDG content in the cortical samples was then determined by comparison with the 8-OHDG standard curve.

\section{Erythropoietin tissue levels}

Tissue concentrations of EPO were measured in duplicate in hippocampal lysates using a commercially available ELISA assay (Quantikine cat \#MEP00, R\&D Systems, Inc, Minneapolis, MN). This assay was linear 
between 22-3,000 pg/ml using a standard calibration curve, and the intra- an inter-individual coefficients of variability were $4.6 \%$ and $8.4 \%$, respectively.

\section{Primary neuronal cell cultures}

Cortical neuronal cells were prepared from fetal mouse brain cortex at embryonic stage 14.5 days (E14.5). Manually dissociated brain cortical cells were plated in a Petri dish coated with poly-L-ornithine $(0.015 \mathrm{~g} / \mathrm{L})$ in a culture medium including neurobasal medium (Gibco), Mix B27(Gibco), L-glutamine 250uM, glutaMax 250uM, Antibiotic/Amycotic (Gibco) 1\%. Half of the media in the wells were removed and replaced with fresh culture medium every 3 days. After 12 days in culture, primary neuronal cells were used for in vitro IH experiments. Cultured cortical neuronal cells were exposed to normoxia or IH respectively in a computer controlled cell incubator chamber that tightly controls $\mathrm{O} 2$ concentrations in the cell culture medium and in the cell culture chambers (Reming Bioinstruments, Redfield, NY). For normoxia treatment, cells were cultured under normal cell culture conditions $\left(37^{\circ} \mathrm{C}, 95 \%\right.$ air and $5 \% \mathrm{CO} 2$ in a humid incubator). For $\mathrm{IH}$ or $\mathrm{SH}$ treatments, cell were treated with either alternations of $35 \mathrm{~min}-5 \% \mathrm{O} 2 / 5 \% \mathrm{CO} 2$ balance $\mathrm{N} 2$ followed by $25 \mathrm{~min}-21 \% \mathrm{O} 2 / 5 \% \mathrm{CO} 2$ balance $\mathrm{N} 2(\mathrm{IH})$ or exposed to $5 \% \mathrm{O} 2 / 5 \% \mathrm{CO} 2$ balance $\mathrm{N} 2(\mathrm{SH})$ for $72 \mathrm{hrs}$ in the presence or absence of pre-treatment with EPO in culture medium $(1,500 \mathrm{pg} / \mathrm{ml})$. Cells were collected, and RNA was isolated and subjected to qRTPCR analysis for NADPH oxidase p47phox subunit expression, as delineated above.

\section{Data analysis}

To elucidate the nature of interactions between $\mathrm{IH}, \mathrm{SH}$, and RA conditions, all data were initially analyzed by one way ANOVA. First, overall statistical significance was determined for the entire training period between the treatment groups. In addition, either two-way repeated measures ANOVA or MANOVA were used to analyze each trial block, followed by post-hoc Tukey tests. Similar statistical approaches were used to compare probe trial, reference memory, EPM and FST. For all comparisons, a $\mathrm{p}$ value $<0.05$ was considered to achieve statistical significance.

In all the experimental conditions, the data were divided into 6 blocks (containing 3 trials/day). We used a multivariate MANOVA model (SPSS software 17; Chicago) that included latency, pathlength and swim speed and two between factors: (1) Groups (four levels): RA-C, IH-C, RA-EPO, and IH-EPO (2) Condition (two levels): RA or IH. All $F$ statistics are reported using Pillai's Trace. The interaction of three different factors, i.e., time, condition and group were determined using this mixed model repeated measures MANOVA.

\section{Results}

\section{EPO and NADPH oxidase expression}

Cortical tissues from IH-, SH, and RA-exposed mice were subjected to quantitative RT-PCR. Compared to normoxia (RA), EPO expression was increased after 1 day $\mathrm{SH}$ and heightened expression levels were sustained throughout the exposures (Figure 1A). However, although a significant, albeit attenuated increase in EPO mRNA occurred with $\mathrm{IH}$, such changes were not sustained (Figure 1A). In contrast, p47 subunit of NADPH oxidase (P47phox) expression was increased in IH starting at 3 days and sustained thereafter (Figure 1B), and such changes were not apparent following $\mathrm{SH}$ (Figure 1B). Although no changes occurred in EPO receptor expression during $\mathrm{IH}$, mild increases in mRNA expression of the EPO receptor emerged after $\mathrm{SH}$ at days 7 and 14 of exposures $(1.8 \pm 0.4$ and $2.1 \pm 0.5$ fold of normoxic controls, respectively; $n=6$; $p<0.03$ ). Furthermore, EPO treatment in $\mathrm{IH}$-exposed mice resulted in significant in vivo reductions in $\mathrm{P} 47$ phox expression (Figure 1C).

In a parallel study using embrionically derived neuronal primary cells, in vitro $\mathrm{IH}$ for 72 hours induced significant increases in P47phox mRNA expression that were not present in SH-exposures (Figure 2). Conversely, marked increases in EPO mRNA occurred after $\mathrm{SH}$, but not after IH (Figure 2). Furthermore, addition of EPO at concentrations similar to those found in brain tissue lysates during $\mathrm{SH}$ (i.e., 1,500 pg/ml), markedly reduced p47phox gene expression during IH (Figure 2).

EPO immunoreactivity was markedly increased in $\mathrm{SH}$-exposed mice, and seemed to co-localize with both NeuN-positively labeled cells and other cells. However, changes were absent or markedly attenuated in IHexposed mice (Figure 3). To further confirm EPO changes in $\mathrm{IH}$ and $\mathrm{SH}$ conditions, EPO protein levels were also assayed in hippocampal lysates harvested from mice exposed to $\mathrm{IH}, \mathrm{SH}$ or normoxic controls ( $\mathrm{n}=8$ /experimental group). $\mathrm{SH}$ was associated with marked increases in EPO tissue ocncentraitons at at all time points, and such increases, although significant when compared to normoxic conditions, were markedly attenuated in $\mathrm{IH}$ exposures (Figure 4). In addition, EPO administration was associated with significant increases in hippocampal EPO tissue ocncentrations (Figure 4).

\section{Effects of IH, SH and EPO on blood hematocrit}

Normoxic mice treated with vehicle had mean hematocrits (Hct) of $34.3 \pm 1.7 \%$ as compared to significant increases in Hct among EPO-treated normoxic mice $(54.5 \pm 3.3 \%$; $\mathrm{p}<0.001)$. $\mathrm{SH}$ exposures were also associated with significant and robust increases in Hct (53.1 $\pm 3.7 \%$; p < 0.001 vs. RA). However, IH exposures 


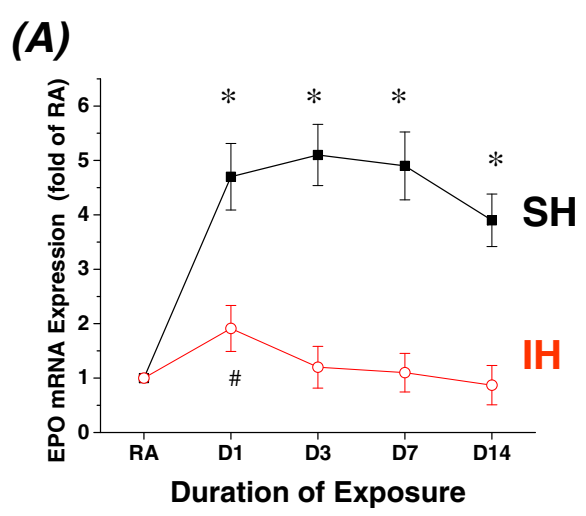

(B)

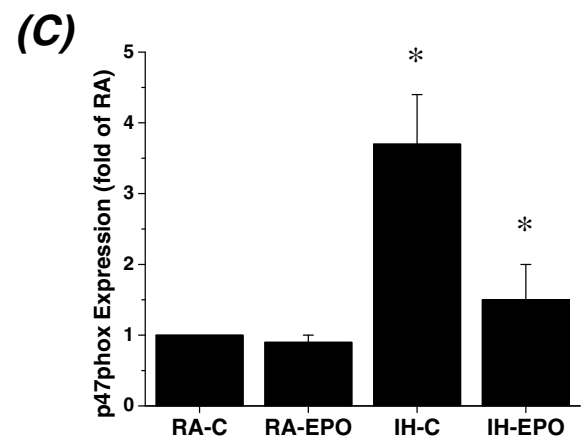

Figure 1 Changes in EPO and P47phox mRNA expression in hippocampus in mice exposed to IH and SH (A). Changes in EPO mRNA expression in hippocampus of mice exposed to $\mathrm{H}$ and $\mathrm{SH}$ compared to normoxic conditions (RA) ( $\mathrm{n}=7$ per time point; ${ }^{*} \mathrm{p}<0.01 \mathrm{H}$ vs. SH; \# $\mathbb{H}$ vs. RA $-p<0.05$ ). (B). Changes in NADPH oxidase P47phox subunit expression in the hippocampus of mice exposed to $H$ and $\mathrm{SH}$ ( $n=7$ per time point; ${ }^{*} \mathrm{p}<0.01 \mathrm{IH}$ vs. SH or RA). (C). Treatment with EPO significantly reduced p47phox subunit expression in the hippocampus of mice exposed to $\mathbb{H}$ for 14 days $(*-p<0.01 ; n=6$ per condition). RA-C and $I H-C$ refer to treatment with vehicle, while RA-EPO and IH-EPO indicate treatment with exogenous EPO.

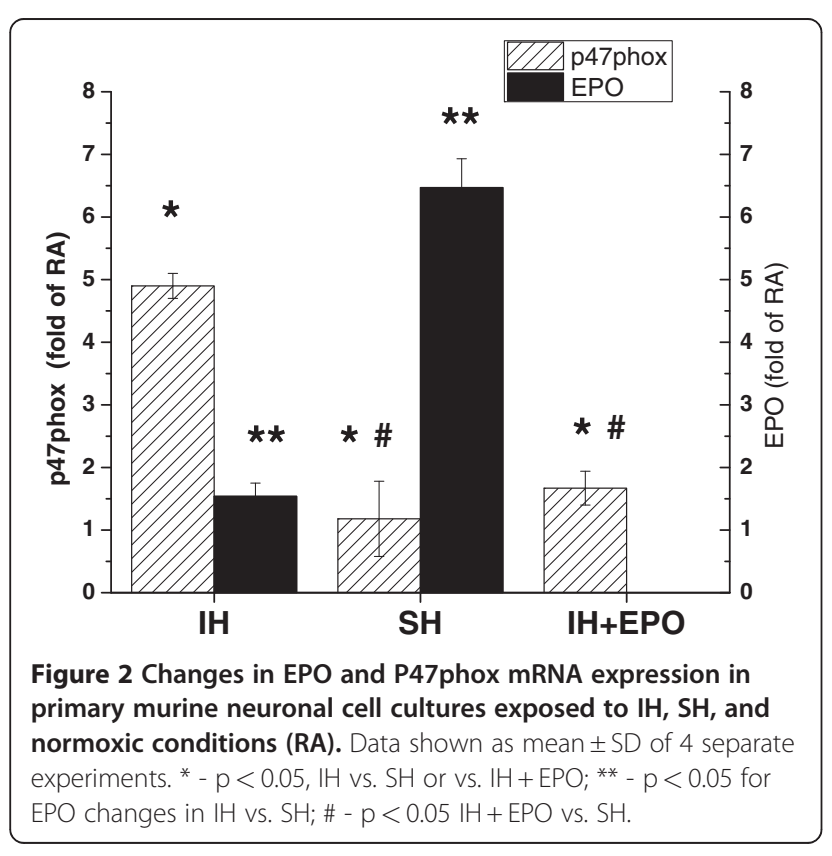

coupled with vehicle treatment did not induce significant changes in Hct $(35.7 \pm 1.3 \%$; $>0.05$ vs. RA). Finally, EPO administration in $\mathrm{IH}$-exposed mice induced substantial increases in Hct $(56.8 \pm 3.1 \%$; $\mathrm{p}<0.001$ vs. $\mathrm{IH}+$ vehicle) that were similar to the effects of EPO in normoxic mice.

\section{Spatial learning performance}

On a standard place discrimination task, wild type mice exposed to 14 days of $\mathrm{IH}$ ( $\mathrm{IH}-\mathrm{C})$ exhibited longer latencies and pathlengths to locate the hidden platform when compared to room air controls RA-C, RA-EPO, and IHEPO mice exposed to 14 days $\mathrm{IH}(\mathrm{n}=24$ per experimental condition; Figure 5A and B). Overall latency analysis for the entire trial blocks revealed significant changes between the different treatment groups, $\left[\mathrm{F}_{(3,51)}=40.22\right.$; $\mathrm{p}<0.001]$ and pathlength, $\left[\mathrm{F}_{(3,51)}=17.63 ; \mathrm{p}<0.001\right]$ indicating that $\mathrm{IH}$ adversely affected task performance in vehicle-treated mice. Significant differences in latencies were observed during blocks $2\left[\mathrm{~F}_{(3,51)}=5.16 ; \mathrm{p}<0.01\right]$, $3\left[\mathrm{~F}_{(3,51)}=12.43 ; \mathrm{p}<0.001\right], 4\left[\mathrm{~F}_{(3,51)}=5.04 ; \mathrm{p}<0.01\right], 5$ $\left[\mathrm{F}_{(3,51)}=10.22 ; \mathrm{p}<0.001\right]$ and $6\left[\mathrm{~F}_{(3,51)}=7.67 ; \mathrm{p}<0.001\right]$. There were no significant differences in block 1 . 


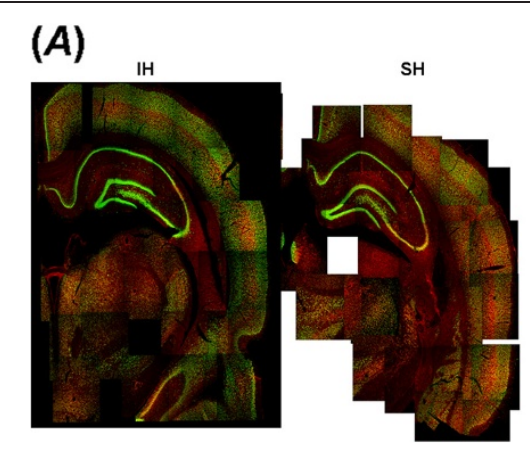

(B)

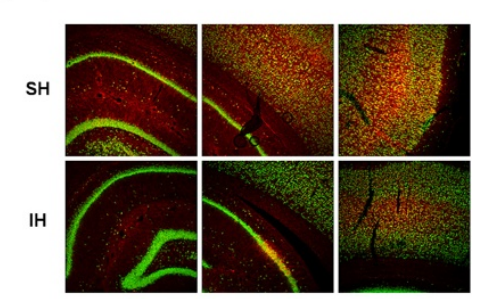

Figure 3 Erythropoietin immunoreactivity in cortex and hippocampus following intermittent and sustained hypoxic exposures in mice. (A). Composite reconstructions of immunohistochemically processed brain sections double labeled for EPO (red fluorescence) and NeuN (green flurorescence) immunoreactivity after $\mathrm{H}$ (left) and SH (right). (B). Illustrative examples of EPO and NeuN labeling of hippocampus and frontal cortex after $\mathrm{H}$ or $\mathrm{SH}$ exposures.

Repeated measures ANOVA revealed significant differences in pathlengths during blocks $3\left[\mathrm{~F}_{(3,51)}=7.25\right.$; $\mathrm{p}<0.001], 4 \quad\left[\mathrm{~F}_{(3,51)}=6.46 ; \mathrm{p}<0.001\right], 5\left[\mathrm{~F}_{(3,51)}=6.58\right.$; $\mathrm{p}<0.001]$ and $6\left[\mathrm{~F}_{(3,51)}=5.04 ; \mathrm{p}<0.02\right]$, with no significant differences in blocks 1 and 2. There were no significant differences in swim speed in these mice. In the probe-trial test, one-way ANOVA revealed a significant effect of treatment [IH vs. RA: $\left.\mathrm{F}_{(3,51)}=15.27 ; \mathrm{p}<0.001\right]$. The magnitude of impairment was greatest in IH-C (Figure 5C). Of note, identical training paradigms in $\mathrm{SH}-$ exposed mice revealed no differences in task-acquisition performance when compared to RA-C, RA-EPO, and IHEPO mice (data not shown). In the reference memory tests, IH-C mice exhibited significant deficits in memory retention in both latency $\left[\mathrm{F}_{(3,51)}=24.47 ; \mathrm{p}<0.001\right]$ and pathlength $\left[\mathrm{F}_{(3,51)}=19.28 ; \mathrm{p}<0.001\right]$. However, the IHEPO mice performed similar to RA-C (Figure 6).

Repeated measures MANOVA with latency, groups and conditions $\left[\mathrm{F}_{(3,51)}=108.4 ; \mathrm{p}<0.001\right]$; revealed that RA-C, RA-EPO, and IH-EPO treated mice as well as SH-exposed mice required significantly less time than $\mathrm{IH}-\mathrm{C}$ to find the hidden platform in a Morris water maze (Figure 5); Repeated measures MANOVA with pathlength, groups and conditions $\left[\mathrm{F}_{(3,51)}=42.9 ; \mathrm{p}<0.001\right]$; indicated that as the training progressed the RA-C, RA-EPO, $\mathrm{SH}$, and $\mathrm{IH}-$ EPO treated mice could reach the hidden platform and covered the shortest distance when compared to the distance covered by IH-C in the Morris water maze

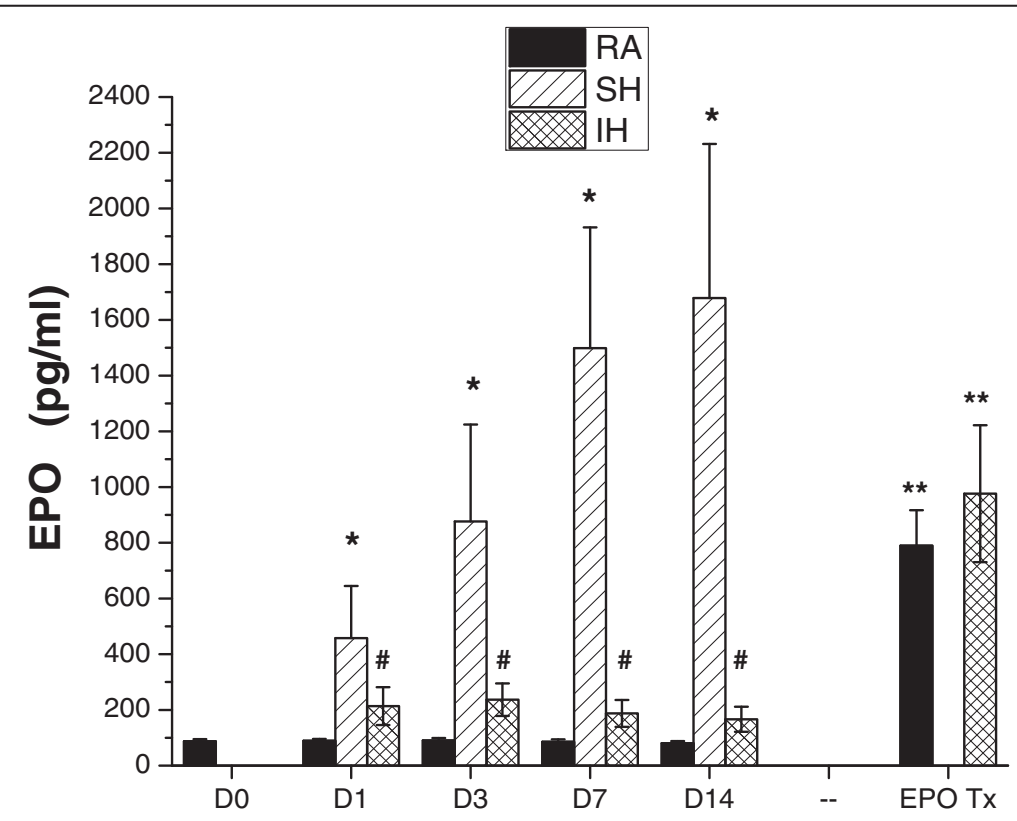

Figure 4 Erythropoietin hippocampal tissue concentration changes in mice exposed to room air (normoxia, RA), IH, and SH for 1, 3, 7

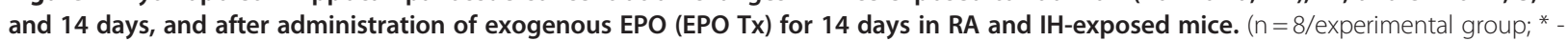
$p<0.01$ SH vs. RA or $I H ; \#-p<0.05 \mathrm{IH}$ vs. RA; ** $-p<0.01 \mathrm{EPO}$ Tx vs. RA and $I H)$. 



Figure $\mathbf{5}$ Erythropoietin-treated mice exposed to IH do not exhibit deficits in learning and memory functions. (A and B) Mean latencies (s) and pathlengths $(\mathrm{cm})$ to locate the target platform during place training in mice either exposed to intermittent hypoxia $(\mathrm{IH})$ or maintained in room air (RA) ( $n=24$ per group; $\left.{ }^{*}-p<0.001\right)$, and receiving either vehicle (C) or EPO. (C) Swim Speed (D) Mean percentage time in the target quadrant during probe trial after completion of water maze testing ( $n=24$ /experimental group; $\left.{ }^{*}-p<0.001\right)$.

(Figure 5). In addition, repeated measures MANOVA with swim speed, groups and conditions on the swim speed showed no significant differences between the groups and treatments (Figure 5).

\section{Elevated plus maze and forced swim test}

IH-C mice, but not IH-EPO mice, showed significant differences in the percentage of time spent in the open arm $\left[\mathrm{F}_{(1,48)}=78.21 ; \mathrm{p}<0.001\right]$ and in the number of entries into the closed arm $\left[\mathrm{F}_{(1,48)}=22.67 ; \mathrm{p}<0.001\right]$ (Figure 7). The results of the elevated plus maze showed that $\mathrm{IH}-\mathrm{C}$ spent significantly less time in the open arms (Figure 5; group effect, $\left.\left[\mathrm{F}_{(1,48)}=22.54 ; \mathrm{p}<0.001\right]\right)$ and significantly more time in the center area (Figure 5; group effect, $[\mathrm{F}$
$(1,48)=32.66 ; \mathrm{p}<0.001])$. The number of entries into the closed arms was significantly increased (Figure 7; condition effect, $\left.\left[\mathrm{F}_{(1,48)}=17.44 ; \mathrm{p}<0.001\right]\right)$. Although, the percentage of time spent in the open arm is commonly used as a measure of anxiety, we should also point out that the time spent on the center platform of the maze and the closed arm entries also reflect anxiety-like behaviors in mice. Similarly, the overall time spent in immobility in the forced swim test was significantly higher in IH-C treated mice, while IH-EPO mice were indistinguishable from normoxic controls (Figure 8).

\section{8-OHDG levels and lipid peroxidation}

The levels of 8-OHDG in homogenates of cerebral cortex (data not shown) and the hippocampus were 

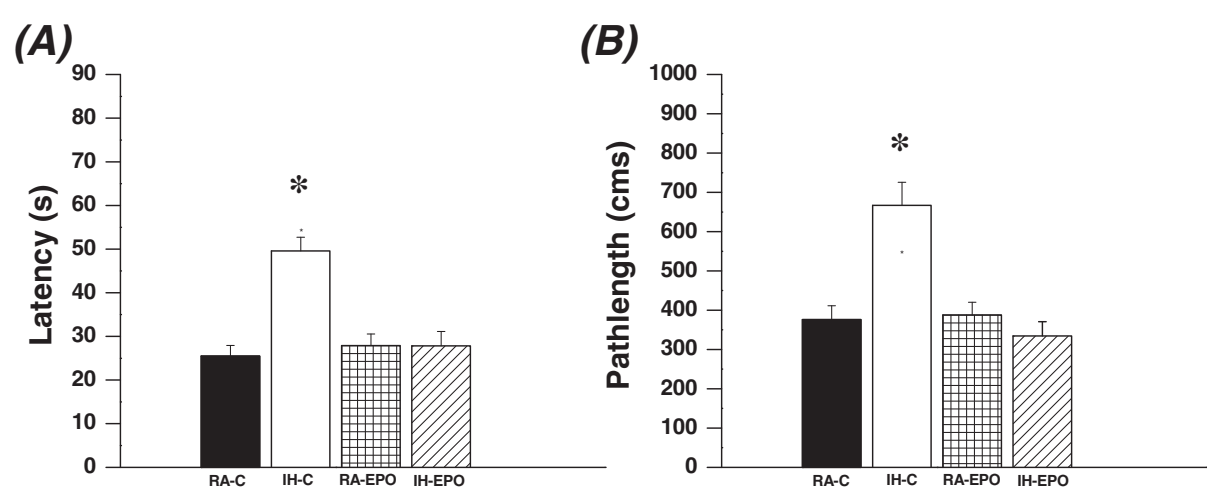

Figure 6 Erythropoietin-treated mice exposed to IH do not exhibit any deficits in retention. (A) Mean latencies (S) and (B) pathlengths $(\mathrm{cm})$ to locate the target platform during retention in mice either exposed to intermittent hypoxia $(\mathrm{IH})$ or maintained in room air (RA), and receiving either EPO or vehicle $(C)$ during retention of the Morris water maze task. ( $n=24 /$ experimental group; $\left.{ }^{*}-p<0.001\right)$.
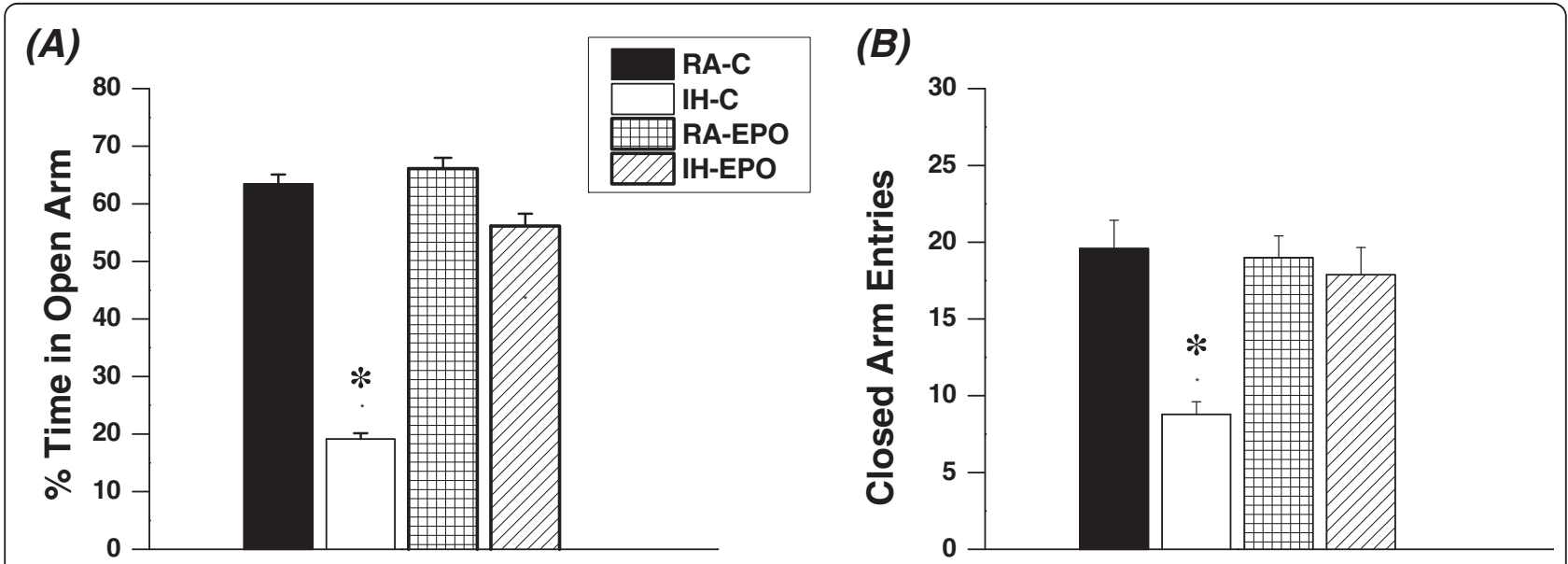

(C)

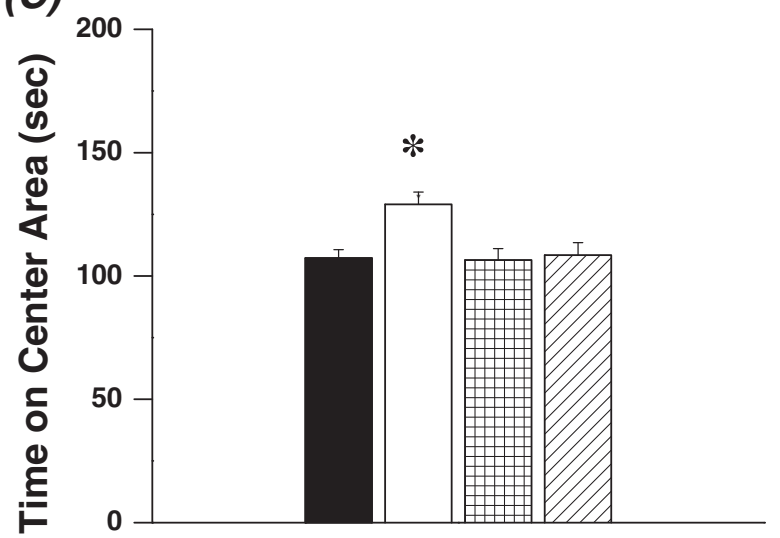

Figure 7 Erythropoietin treatment prevents $\mathrm{IH}$-induced anxiety in mice. (A). Mice exposed to $\mathbb{H}$ and treated with vehicle (IH-C) spend significantly less time in the open arm of the elevated plus maze compared to IH-EPO, RA-EPO, or RA-C mice ( $n=18$ /experimental group; $\left.{ }^{*}-p<0.001\right)$. (B). A reduced number of closed-arm entries emerged in mice exposed to $\mathrm{H}$ and treated with vehicle $\left(n=18 /\right.$ experimental group; ${ }^{*}-$ $\mathrm{p}<0.001)$. (C). Time spend in the Center Area was increased in mice exposed to $\mathbb{H}$ and treated with vehicle $\left(n=18 /\right.$ experimental group; ${ }^{*}$ $p<0.001)$. 


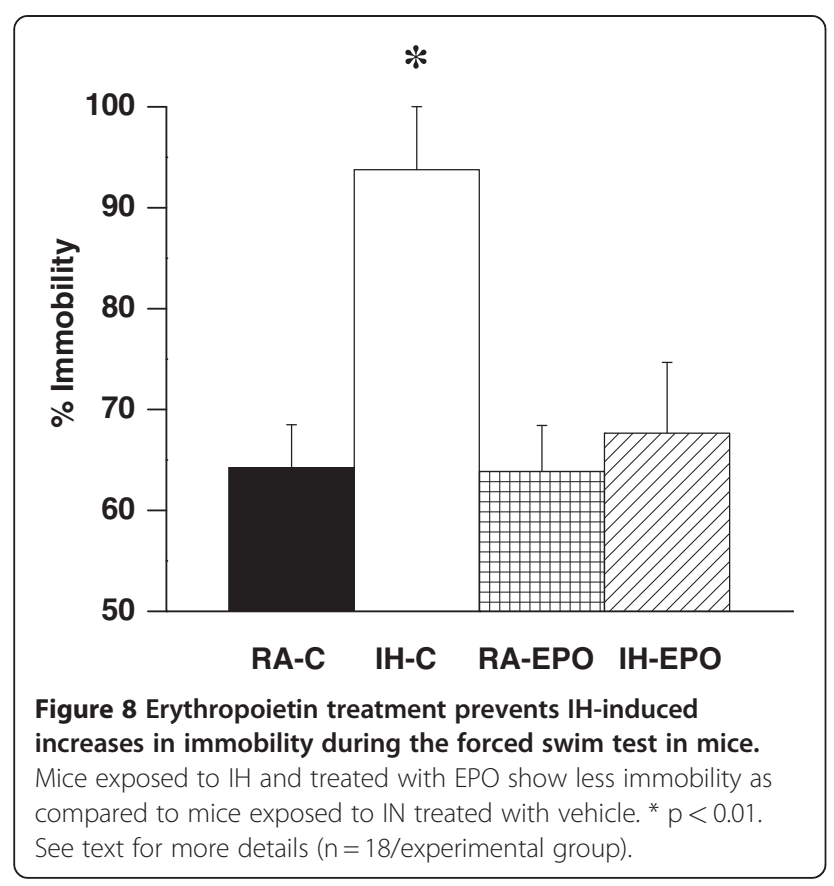

significantly higher in $\mathrm{IH}-\mathrm{C}$ mice $\left[\mathrm{F}_{(1,32)}=44.72\right.$; $\mathrm{p}<0.01]$ and $\left[\mathrm{F}_{(1,32)}=31.64 ; \mathrm{p}<0.0001\right]$ respectively; when compared to all other groups (Figure 9A). However there were no significant differences in the levels of 8-OHDG in cortex of IH-EPO when compared to either RA-C or RA-EPO controls.

Figure 9B shows MDA concentrations in homogenates of cerebral cortex from all treatment groups. A significant increase in MDA levels was observed in IH-C mice $\left[\mathrm{F}_{(1,32)}=22.41 ; \quad \mathrm{p}<0.001\right] \quad$ in the cortex and $[\mathrm{F}$ $(1,32)=69.13 ; \mathrm{p}<0.01]$ in the hippocampus when compared to all other groups.

\section{Discussion}

OSA is a highly prevalent clinical condition across the lifespan that imposes important adverse neurobehavioral consequences. The neurocognitive and behavioral morbidity that frequently accompanies this disease stems, at least in part, from pathological inflammatory and oxidative stress processes recruited by the intermittent hypoxia that characterizes OSA $[9,32]$. Indeed, chronic IH has been shown to induce increased cellular levels of ROS that contribute to end-organ injury, including the CNS, a finding that is not present in $\mathrm{SH}$ of similar magnitude [3]. In the present study, we provide evidence that in contrast with SH exposures, episodic hypoxic events elicit only a shortlived increase in EPO expression in the brain, and conversely induce marked increases in the expression of NADPH oxidase that are absent following SH. Taken together these findings point to an imbalance between injury and defense mechanisms that is tilted towards generation of end-organ damage and dysfunction in $\mathrm{IH}$. However, when EPO treatment was administered, marked reductions in lipid peroxidation and DNA oxidative damage emerged, even during IH. Consequently, cognitive and behavioral deficits associated with $\mathrm{IH}$ were markedly attenuated by EPO administration, suggesting that harnessing of the EPO pathway response will afford neuronal protection against the oxidative and inflammatory processes elicited by IH during sleep.

The increased expression of NADPH oxidase during $\mathrm{IH}$ was anticipated, and confirms previous work by Zhan and colleagues [33] and our recent work [10], showing that $\mathrm{NADPH}$ oxidase null mice are protected from $\mathrm{IH}$-induced cognitive deficits. Of note, other ROS-generating pathways are putatively implicated in the cognitive and behavioral deficits associated with $\mathrm{IH}$ exposures, and reductions in oxidative stress and inflammatory signaling cascades through pharmacological interventions, and through attenuation of oxidative stress via targeted genetic manipulations of several identified target genes will all reduce or abrogate CNS dysfunction [3,9,12,13,15,34].

Depression and anxiety symptoms are frequent in OSA patients [35]. The elevated plus-maze is the most
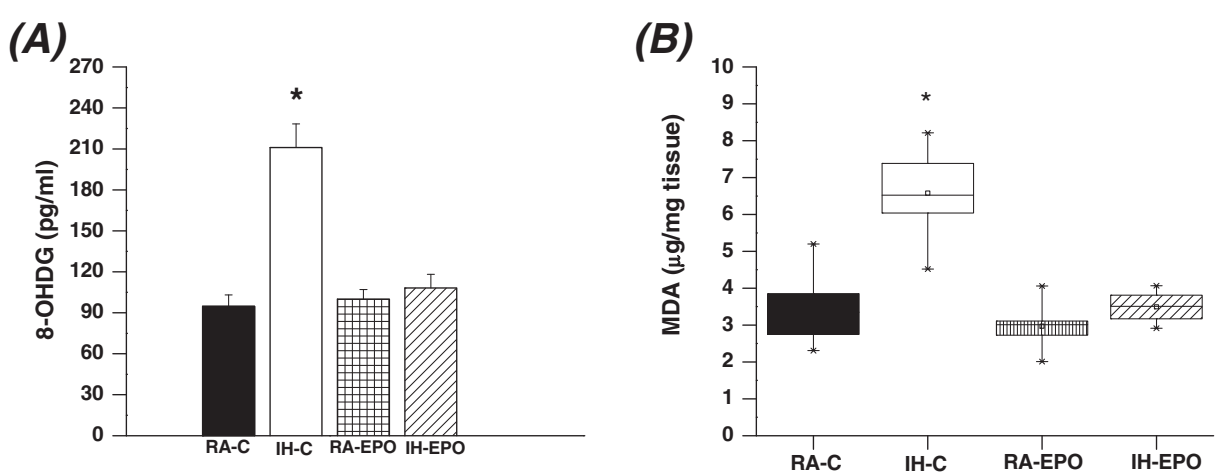

Figure 9 Erythropoietin treatment reduces oxidative DNA damage and lipid peroxidation following IH exposures in mice. 8-OHDG (A) hippocampal tissue levels and cortical MDA levels (B) in mice exposed to either room air (RA) or intermittent hypoxia and treated with either EPO or vehicle $(\mathbf{C})$. $\left(n=8\right.$ per experimental group; $\left.{ }^{*} p<0.001\right)$. 
frequently utilized animal model for assessing anxietylike behaviors [27], and provides the setting for a conflict between two innate rodent behaviors, namely avoidance of open space exposures and the tendency to explore novel environments [36]. Our current findings show that IH modified anxiety-like behavior in vehicle-treated mice exposed to $\mathrm{IH}$, and that such changes in elevated maze performance disappeared upon administration of EPO, suggesting that regions underlying these behavioral responses are susceptible to $\mathrm{IH}$, and the associated oxidant stress. Of note, a palliative effect on neuronal viability has been reported for apocynin, a putative $\mathrm{NADPH}$ oxidase antagonist in animals exposed to $\mathrm{IH}$ [37]. In this context, it is worthwhile to emphasize that there are multiple possible sources for oxidative stress in the context of IH [32], and it is therefore likely that such multiple sources may not only adversely affect cognitive function and EPO transcription in $\mathrm{IH}$, but also that exogenous EPO administration may differentially influence the magnitude of oxidative stress in these various compartments. These issues will obviously have to await additional studies.

Considering the consensus view that assigns a coordinated role for a number of interrelated pathways, i.e., glutamate excitoxicity, oxidative stress, mitochondrial dysfunction, up-regulation of pro-inflammatory mediators, and altered regulation of pro- and anti-apoptotic gene cascades in the injurious processes associated with $\mathrm{IH}$ in the CNS $[7,38]$, the protective role of EPO appears to be well justified by the previous evidence indicating that EPO is indeed operative in many of these pathways. EPO is a typical HIF-1 $\alpha$-dependent cytokine that has now conclusively been shown to be expressed and induced in both neuronal and glial cell populations [17]. In the last decade, multiple lines of evidence have shown that both endogenous and exogenous EPO has protective roles in CNS injury processes, such as ischemiareperfusion injury [19,20,39-44]. Although the presence of functional EPO receptors in neurons has been challenged [45], EPO selectively reduced inflammatory and oxidative stress processes associated with brain ischemia, and prevented neuronal apoptosis [44]. Our current findings show that the modality of the hypoxic exposure is critically important for the induction of EPO expression, and that in contrast with $\mathrm{SH}$, chronic $\mathrm{IH}$ does not result in increased EPO expression, despite similar oxyhemoglobin desaturation levels in the 2 conditions. In this context, we are unaware of specific comparisons between $\mathrm{IH}$ and $\mathrm{SH}$ and their effect on HIF- $1 \alpha$ transcribed genes in the CNS. However, studies on other tissues such as endothelial cells [46], or perinatal adrenal chromaffin cells [38], have yielded conflicting results. Indeed, either similar or divergent HIF-1 $\alpha$ changes have been reported. Of note, we have recently shown that $\mathrm{SH}$ is not accompanied by significant deficits on a spatial hippocampal task in rats $[3,11]$, and our findings in the current study extend these observations to mice. Accordingly, systemic treatment with rhEPO, which has been shown to cross the blood brain barrier [22,23], conferred a protective effect again $\mathrm{IH}$-induced oxidative stress, and prevented the cognitive and behavioral deficits associated with $\mathrm{IH}$. Notwithstanding, it is possible that EPO-mediated beneficial effects may be also related to changes in angiogenesis and the cerebral microvasculature $[47,48]$. Indeed, evidence in children would support this assumption whereby changes in blood flow and endothelial function have been linked to cognitive function in children with sleep apnea $[49,50]$.

\section{Conclusions}

In summary, we have shown that prolonged $\mathrm{SH}$, but not $\mathrm{IH}$, induces the expression of EPO in the CNS, and the reciprocal effect occurs in the expression of NADPH oxidase during these 2 hypoxic exposures. Furthermore, we have shown that exogenous administration of EPO during the course of $\mathrm{IH}$ exposures mitigates the cellular oxidative stress damage and consequent behavioral impairments associated with this murine model of OSA. Although a direct mechanistic pathway can be definitively established between EPO and NADPH oxidase in the context of hypoxia-induced CNS susceptibility, this study suggests that efforts aiming to increase either EPO expression or the activation of EPO receptors in the CNS may be a promising target for OSA treatment, especially in stopping the progression, and potentially reversing the well known OSA-associated cognitive and behavioral morbidities.

\section{Competing interests}

The authors declare that they have no competing interests.

\section{Acknowledgments}

We are grateful to Yu Cheng for her technical assistance with behavioral testing and to Kenneth $\mathrm{R}$ Brittian for his contributions during immunohistochemistry procedures

\section{Financial support}

This study was supported by National Institutes of Health grant HL-086662.

\section{Author details}

${ }^{1}$ Department of Pediatrics, Pritzker School of Medicine, Comer Children's Hospital, The University of Chicago, 5721 S. Maryland Avenue, Suite K-160, Chicago, IL MC 8000, USA. ${ }^{2}$ Biomolecular Science Center, Burnett College of Biomedical Sciences, University of Central Florida, Orlando, FL, USA.

\section{Authors' contributions}

ED and SW carried out the majority of the experiments, JZC performed immunohistochemistry imaging experiments, YW participated in study design and troubleshooting of some of the technical aspects of the project as well as data analysis, and DG was responsible for the conceptual framework of the project and its funding, as well as data analysis and drafting of the manuscript. All authors read and approved the final manuscript. 
Received: 5 November 2011 Accepted: 18 June 2012

Published: 3 July 2012

\section{References}

1. Bernaudin M, Bellail A, Marti HH, Yvon A, Vivien D, Duchatelle I, Mackenzie $E T$, Petit E: Neurons and astrocytes express EPO mRNA: oxygen-sensing mechanisms that involve the redox-state of the brain. Glia 2000, 30:271278.

2. Burckhardt IC, Gozal D, Dayyat E, Cheng Y, Li RC, Goldbart AD, Row BW: Green tea catechin polyphenols attenuate behavioral and oxidative responses to intermittent hypoxia. Am J Respir Crit Care Med 2008, 177:1135-1141.

3. Li RC, Guo SZ, Raccurt M, Moudilou E, Morel G, Brittian KR, Gozal D: Exogenous growth hormone attenuates cognitive deficits induced by intermittent hypoxia in rats. Neuroscience 2011, 196:237-250.

4. Canessa N, Castronovo V, Cappa SF, Aloia MS, Marelli S, Falini A, Alemanno F, Ferini-Strambi L: Obstructive sleep apnea: Brain structural changes and neurocognitive function before and after treatment. Am J Respir Crit Care Med 2011, 183:1419-1426.

5. Macey PM, Henderson LA, Macey KE, Alger JR, Frysinger RC, Harper RM: Brain morphology associated with obstructive sleep apnea. Am J Respir Crit Care Med 2002, 166:1382-1387.

6. Goldbart AD, Row BW, Kheirandish L, Cheng Y, Brittian KR, Gozal D: High fat/refined carbohydrate diet enhances the susceptibility to spatial learning deficits in rats exposed to intermittent hypoxia. Brain Res 2006, 1090:190-196.

7. Gozal D, Daniel JM, Dohanich GP: Behavioral and anatomical correlates of chronic episodic hypoxia during sleep in the rat. J Neurosci 2001, 21:2442-2450.

8. Gozal D, McLaughlin Crabtree V, Sans Capdevila O, Witcher LA, KheirandishGozal L: C reactive protein, obstructive sleep apnea, and cognitive dysfunction in school-aged children. Am J Respir Crit Care Med 2007, 176:188-193.

9. Kheirandish L, Row BW, Li RC, Brittian KR, Gozal D: Apolipoprotein E deficient mice exhibit increased vulnerability to intermittent hypoxiainduced spatial learning deficits. Sleep 2005, 28:1412-1417.

10. Nair D, Dayyat EA, Zhang SXL, Wang Y, Gozal D: Intermittent hypoxiainduced cognitive deficits are mediated by NADPH oxidase activity. PLOS One 2011, 6(5):e19847.

11. Payne RS, Goldbart AD, Gozal D, Schurr A: Effect of intermittent hypoxia on long-term potentiation in rat hippocampal slices. Brain Res 2004, 1029:195-199.

12. Row BW, Liu R, Xu W, Kheirandish L, Gozal D: Intermittent hypoxia is associated with oxidative stress and spatial learning deficits in the rat. Am J Respir Crit Care Med 2003, 167:1548-53.

13. Row BW, Kheirandish L, Li RC, Hardie M, Bazan NG, Gozal D: Plateletactivating factor receptor deficient mice are protected from experimental sleep apnea-induced spatial learning deficits. J Neurochem 2004, 89:189-196.

14. Shan X, Chi L, Ke Y, Luo C, Qian SY, St Clair D, Gozal D, Liu R: Manganese superoxide dismutase protects mouse cortical neurons from chronic intermittent hypoxia-mediated oxidative damage. Neurobiol Dis 2007, 28 (2):206-215

15. Xu W, Chi L, Row BW, Xu R, Ke Y, Xu B, Luo C, Kheirandish L, Gozal D, Liu R: Increased oxidative stress is associated with chronic intermittent hypoxia-mediated brain cortical neuronal cell apoptosis in a mouse model of sleep apnea. Neuroscience 2004, 126:313-323.

16. Jun J, Savransky V, Nanayakkara A, Bevans S, Li J, Smith PL, Polotsky VY: Intermittent hypoxia has organ-specific effects on oxidative stress. Am J Physiol Regul Integr Comp Physiol 2008, 295:R1274-R1281.

17. Marti HH, Wenger RH, Rivas LA, Straumann U, Digicaylioglu M, Henn V, Yonekawa Y, Bauer C, Gassmann M: Erythropoietin gene expression in human, monkey and murine brain. Eur J Neurosci 1996, 8:666-676.

18. Sakanaka M, Wen TC, Matsuda S, Masuda S, Morishita E, Nagao M, Sasaki R: In vivo evidence that erythropoietin protects neurons from ischemic damage. Proc Natl Acad Sci U S A 1998, 95:4635-4640.

19. Sanchez PE, Fares RP, Risso JJ, Bonnet C, Bouvard S, Le-Cavorsin M, Georges B, Moulin C, Belmeguenai A, Bodennec J, Morales A, Pequignot JM, Baulieu EE, Levine RA, Bezin L: Optimal neuroprotection by erythropoietin requires elevated expression of its receptor in neurons. Proc Natl Acad SCi U S A 2009, 106:9848-9853.
20. Siren AL, Fratelli M, Brines M, Goemans $C$, Casagrande $S$, Lewczuk P, Keenan S, Gleier C, Pasquali C, Capobianco A, Mennini T, Heumann R, Cerami A, Ehrenheich $H$, Ghezzi P: Erythropoietin prevents neuronal apoptosis after cerebral ischemia and metabolic stress. Proc Natl Acad Sci U S A 2001, 98:4044-4049.

21. Montplaisir J, Bédard MA, Richer F, Rouleau I: Neurobehavioral manifestations in obstructive sleep apnea syndrome before and after treatment with continuous positive airway pressure. Sleep 1992, 15:S17-S19.

22. Banks WA, Jumbe NL, Farrell CL, Niehoff ML, Heatherington AC: Passage of erythropoietic agents across the blood-brain barrier: a comparison of human and murine erythropoietin and the analog darbepoetin alfa. Eur J Pharmacol 2004, 505:93-101.

23. Brines ML, Ghezzi P, Keenan S, Agnello D, de Lanerolle NC, Cerami C, Itri LM, Cerami A: Erythropoietin crosses the blood-brain barrier to protect against experimental brain injury. Proc Natl Acad Sci U S A 2000 97:10526-10531

24. Statler PA, McPherson RJ, Bauer LA, Kellert BA, Juul SE: Pharmacokinetics of high-dose recombinant erythropoietin in plasma and brain of neonatal rats. Pediatr Res 2007, 61:671-675.

25. Morris R: Developments of a water-maze procedure for studying spatial learning in the rat. J Neurosci Methods 1984, 11:47-60.

26. Gerlai R, Clayton NS: Analysing hippocampal function in transgenic mice: an ethological perspective. Trends Neurosci 1999, 22:47-51.

27. File SE: Behavioural detection of anxiolytic action. In Experimental Approaches to Anxiety and Depression. Edited by Elliot JM, Heal DJ, Marsden CA. New York: John Wiley \& Sons; 1992:25-44.

28. Montgomery KC: The relation between fear induced by novel stimulation and exploratory behavior. J Comp Physiol Psychol 1955, 48:254-260.

29. Eckeli AL, Dach F, Rodrigues ALS: Acute treatment with GMP produces antidepressant-like effects in mice. NeuroRep 2000, 11:1839-1843.

30. Kaster MP, Raupp I, Binfaré RW, Andreatini R, Rodrigues SAC Antidepressant-like effect of lamotrigine in the mouse forced swimming test: evidence for the involvement of noradrenergic system. Eur $J$ Pharmacol 2007, 565:119-124.

31. Zomkowski AD, Hammes L, Lin J, Calixto JB, Santos AR, Rodrigues AL: Agmatine produces antidepressant-like effects in two models of depression in mice. Neuroreport 2002, 13:387-391.

32. Wang $Y$, Zhang SXL, Gozal D: Reactive oxygen species and the brain in sleep apnea. Respir Physiol Neurobiol 2010, 174:307-316.

33. Zhan G, Serrano F, Fenik P, Hsu R, Kong L, Pratico D, Klann E, Veasey SC: $\mathrm{NADPH}$ oxidase mediates hypersomnolence and brain oxidative injury in a murine model of sleep apnea. Am J Respir Crit Care Med 2005, 172:921-929.

34. Gozal D, Nair D, Goldbart AD: Physical activity attenuates intermittent hypoxia-induced spatial learning deficits and oxidative stress. Am J Respir Crit Care Med 2010, 182:104-112

35. Akashiba T, Kawahara S, Akahoshi T: Relationship between quality of life and mood or depression in patients with severe obstructive sleep apnea syndrome. Chest 2002, 122:861-865.

36. Pellow S, Chopin P, File SE, Briley M: Validation of open-closed arm entries in an elevated plus-maze as a measure of anxiety in the rat. $J$ Neurosci Methods 1985, 14:149-167.

37. Hui-guo L, Kui L, Yan-ning Z, Yong-jian X: Apocynin attenuates spatia learning deficits and oxidative responses to intermittent hypoxia. Sleep Med 2010, 11:205-212.

38. Brown ST, Buttigieg J, Nurse CA: Divergent roles of reactive oxygen species in the responses of perinatal adrenal chromaffin cells to hypoxic challenges. Respir Physiol Neurobiol 2010, 174:252-258.

39. Iliana S, Yuneidys M, Jorge DG, Nelvis S, Janette C, Adriana M, Yanier N, Julio CG: Recombinant human erythropoietin as a neuroprotective therapy in brain ischemia. Pharmacol Online 2008, 25:223-229.

40. Sirén AL, Knerlich F, Poser W, Gleiter $\mathrm{CH}$, Bruck W, Ehrenreich $\mathrm{H}$ : Erythropoietin and erythropoietin receptor in human ischemic/hypoxic brain. Acta Neuropathol 2001, 101:271-276.

41. Sirén AL, Radyushkin K, Boretius S, Kämmer D, Riechers CC, Natt O, Sargin D, Watanabe T, Sperling S, Michaelis T, Price J, Meyer B, Frahm J, Ehrenreich H: Global brain atrophy after unilateral parietal lesion and its prevention by erythropoietin. Brain 2006, 129:480-489.

42. Villa P, Bigini P, Mennini T, Agnello D, Laragione T, Cagnotto A, Viviani B, Marinovich M, Cerami A, Coleman TR, Brines M, Ghezzi P: Erythropoietin 
selectively attenuates cytokine production and inflammation in cerebral ischemia by targeting neuronal apoptosis. J Exp Med 2003, 198:971-975.

43. Yu YP, Xu QQ, Zhang Q, Zhang WP, Zhang LH, Wei EQ: Intranasal recombinant human erythropoietin protects rats against focal cerebral ischemia. Neurosci Lett 2005, 387:5-10.

44. Zhang F, Signore AP, Zhou Z, Wang S, Cao G, Chen J: Erythropoietin protects CA1 neurons against global cerebral ischemia in rat: potential signaling mechanisms. J Neurosci Res 2006, 83:1241-1251.

45. Sinclair AM, Coxon A, McCaffery I, Kaufman S, Paweletz K, Liu L, Busse L, Swift S, Elliott S, Begley CG: Functional erythropoietin receptor is undetectable in endothelial, cardiac, neuronal, and renal cells. Blood 2010, 115(21):4264-4272. 27.

46. Polotsky VY, Savransky V, Bevans-Fonti S, Reinke C, Li J, Grigoryev DN, Shimoda LA: Intermittent and sustained hypoxia induce a similar gene expression profile in the human aortic endothelial cells. Physiol Genomics 2010, [Epub ahead of print].

47. Kawachi K, Iso Y, Sato T, Wakabayashi K, Kobayashi Y, Takeyama Y, Suzuki H. Effects of erythropoietin on angiogenesis after myocardial infarction in porcine. Heart Vessels 2012, 27:79-88.

48. Ning R, Xiong Y, Mahmood A, Zhang Y, Meng Y, Qu C, Chopp M: Erythropoietin promotes neurovascular remodeling and long-term functional recovery in rats following traumatic brain injury. Brain Res 2011, 1384:140-150.

49. Gozal D, Kheirandish-Gozal L, Bhattacharjee R, Spruyt S: Neurocognitive and endothelial dysfunction are frequently concordant in children with OSA. Pediatrics 2010, 126:e1161-e1167.

50. Hogan AM, Hill CM, Harrison D, Kirkham FJ: Cerebral blood flow velocity and cognition in children before and after adenotonsillectomy. Pediatrics. 2008;122:75-82. Erratum in. Pediatrics 2008, 122:689-690.

doi:10.1186/1471-2202-13-77

Cite this article as: Dayyat et al.: Exogenous erythropoietin administration attenuates intermittent hypoxia-induced cognitive deficits in a murine model of sleep apnea. BMC Neuroscience 2012 13:77.

\section{Submit your next manuscript to BioMed Central and take full advantage of:}

- Convenient online submission

- Thorough peer review

- No space constraints or color figure charges

- Immediate publication on acceptance

- Inclusion in PubMed, CAS, Scopus and Google Scholar

- Research which is freely available for redistribution 